\title{
Sugar composition of dietary fibre and short-chain fatty acid production during in vitro fermentation by human bacteria
}

\author{
BY VALÉRIE SALVADOR, CHRISTINE CHERBUT*, JEAN-LUC BARRY, \\ DOMINIQUE BERTRAND, CHRISTIAN BONNET \\ AND JEAN DELORT-LAVAL
}

INRA, Laboratory of Nutrition and Applied Technology, B.P.527, 44026 Nantes Cédex 03, France

(Received 16 June 1992 - Accepted 5 August 1992)

\begin{abstract}
The aim of the present study was to assess the relationship between the disappearance of dietary fibre sugars and the production of individual short-chain fatty acids (SCFA). The bacterial degradation of five dietary fibres whose sugars were quantified was investigated in vitro using a human faecal inoculum. Involvement of the main fibre sugars in SCFA production was evaluated by a stepwise multiple linear regression. The results show first that the nature and chiefly the associations between the fibre sugars were key variables in the fermentability. Second, the nature and the amounts of SCFA produced were closely related to the in vitro fermentation of the main sugars available: uronic acids seemed to be principally involved in the production of acetic acid whereas the production of propionic acid could be promoted by the fermentation of glucose and, to a lesser extent, by that of xylose and arabinose. Xylose tended to have a greater impact than uronic acids and glucose on the production of butyric acid. Thus, it would be possible to predict which SCFA could be specifically produced during the fermentation of a fibre, as far as the chemical composition and structure of this fibre are known.
\end{abstract}

Dietary fibre: Sugars: Fermentation: Short-chain fatty acids

Fermentative breakdown of dietary fibre in the colon produces gases and short-chain fatty acids (SCFA) and influences the physiological and metabolic functions of animals and humans (Sakata, 1987; Nishina \& Freedland, 1990; Cherbut et al. 1991; Titgemeyer et al. 1991). Many studies indicate that the rate and extent of fibre fermentation depend on their botanical origin, chemical composition and physico-chemical properties (Van Soest et al. 1983; McBurney et al. 1985; McBurney \& Thompson, 1989, 1990).

Dietary fibre is composed of complex arrangements of sugars. When isolated, monomers are specifically utilized in vitro by the colonic bacteria (Barry et al. 1989) and their metabolism results in different production patterns of SCFA (Mortensen et al. 1988). As a whole, these results suggest that it is largely the sugar composition of fibre which controls the fermentation process. However, the architecture of the cell wall and the linkages between monomers may change the sugar fermentability and turn the metabolism products into specific SCFA (Titgemeyer et al. 1991). When they are arranged in complex structures in the plant cell wall the sugars are broken down through mechanisms which are still unknown.

In the present work the bacterial degradation of fibre sugars was followed using a system of fermentation in vitro with human faecal bacteria, previously described and validated (Barry et al. 1989; Auffret et al. 1991). Moreover, the relationship between the disappearance of sugars and the production of individual SCFA was assessed.

\footnotetext{
* For reprints.
} 


\section{MATERIALS AND METHODS}

\section{Chemical composition of dietary fibre}

Five fibres were prepared from wheat bran, sugar beet, maize, pea hulls and cocoa by mechanical processes (grinding, air-classification, sieving and drying) and ground to the same average particle size $(0.06$ (SEM 0.02$) \mathrm{mm})$. Their composition is presented in Table 1 . Native wheat bran and maize were prepared by amylase $(E C 3.2 .1 .1 ; 3.2 .1 .3)$ digestion to remove starch (Prosky et al. 1988). The neutral and acidic sugars of the fibres were determined by gas-liquid chromatography (Hoebler et al. 1989) and colorimetry (Thibault, 1979) respectively after the five fibres and their in vitro fermentation residues were hydrolysed at $35^{\circ}$ for $1 \mathrm{~h}$ in $\mathrm{H}_{2} \mathrm{SO}_{4}(720 \mathrm{~g} / \mathrm{kg})$.

\section{In vitro fermentation}

Fresh faeces were collected from healthy subjects accustomed to eating an unspecified Western diet. The faecal inocula were mixed $(1: 3, \mathrm{w} / \mathrm{v})$ with a $\mathrm{CO}_{2}$-saturated nutritive buffer (Table 2) and then filtered through six gauzes to remove non-digested materials. Faecal contents, solutions and containers were kept under a constant flow of $\mathrm{CO}_{2}$ during inoculum preparation. Two experiments were performed. For each experiment two batches of each fibre were prepared by mixing $400 \mathrm{mg}$ fibre with $20 \mathrm{ml}$ human faecal inoculum in a $\mathrm{N}_{2}$ atmosphere. A control batch containing only $20 \mathrm{ml}$ faecal inoculum was also prepared and incubated for $24 \mathrm{~h}$. At time zero the batches were put into a water-bath at $40^{\circ}$. The time course of fermentation was followed by measuring total gas production each hour. The fermentations were stopped at 6,12 and $24 \mathrm{~h}$ of incubation by adding $0.1 \mathrm{ml} \mathrm{HgCl}_{2}$ $(100 \mathrm{~g} / \mathrm{l})$. In the batches removed for analysis the $\mathrm{pH}$ of the medium was immediately measured and bottles were rinsed with $20 \mathrm{ml}$ distilled water. The mixture was centrifuged for $10 \mathrm{~min}$ at $5000 \mathrm{~g}$. Supernatants were analysed for SCFA by gas-liquid chromatography (Jouany, 1982) and the pellets were analysed for cell wall sugars as described earlier.

\section{Calculations and statistical analysis}

The fermentability of each sugar (S), i.e. the rate of $\mathbf{S}$ disappearance, was calculated as follows: initial amount of $S=$ amount of $S$ in the fibre + amount of $S$ in the inoculum, amount of digested $S=$ initial amount of $S-$ amount of $S$ in the residue,

$$
\text { S fermentability }(\%)=100 \times(\text { amount of S digested } / \text { initial amount of S }) \text {. }
$$

The monosaccharides quantified in both native and fermented fibres were expressed as polymers $(0.9 \times$ weight of monosaccharide). To evaluate the involvement of the main fibre sugars in SCFA production a multiple linear regression was performed by using a stepwise regression procedure (Statview SE + Graphics, 1987-1988 Abacus Concepts, Inc., California, USA). The four predictive variables considered were the amounts of arabinose, xylose, glucose and uronic acid which disappeared during the fermentation. They were tested in three equations corresponding to the production (mmol/l) of acetic, propionic and butyric acids respectively. This stepwise regression started with no variables in the equation of SCFA production. The variable with the highest partial correlation was inserted in the model if its partial $F$ value exceeded the level defined to enter, which corresponded to a probability level of $5 \%$. After the insertion of a variable, any variable currently in the model was examined for removal based on whether its probability was less than the level defined to remove $(P>0.05)$. Additional variables were selected or discarded from the equation in the same way. This procedure continued until no variables currently in the equation could be removed and the variable with the highest partial correlation not 
Table 1. Chemical composition (\% of dry matter) of fibre material*

\begin{tabular}{lccrrrr}
\hline \hline Source of fibre & Ash & $\begin{array}{c}\text { Crude } \\
\text { protein }\end{array}$ & Starch & TF & SF & $\begin{array}{c}\text { Lignin } \\
\text { (Klason) }\end{array}$ \\
Wheat bran & $6 \cdot 1$ & $15 \cdot 1$ & $22 \cdot 9$ & $52 \cdot 7$ & $9 \cdot 2$ & $10 \cdot 9$ \\
Sugar beet & $4 \cdot 4$ & $8 \cdot 7$ & $1 \cdot 5$ & $75 \cdot 5$ & $14 \cdot 0$ & $5 \cdot 4$ \\
Maize & $1 \cdot 8$ & $3 \cdot 2$ & $14 \cdot 3$ & $66 \cdot 2$ & $2 \cdot 6$ & $6 \cdot 7$ \\
Pea & $2 \cdot 4$ & $3 \cdot 0$ & $1 \cdot 2$ & $88 \cdot 1$ & $4 \cdot 9$ & $2 \cdot 3$ \\
Cocoa & $9 \cdot 2$ & $14 \cdot 2$ & $0 \cdot 0$ & $81 \cdot 1$ & $18 \cdot 8$ & $29 \cdot 1$ \\
\hline
\end{tabular}

TF, total fibre; SF, soluble fibre.

* For details of procedures, see p. 190.

Table 2. Composition $(g / l)$ of the nutritive buffer mixed with the faecal inocula $(1: 3 w / v)$ to prepare the fermentation medium*

\begin{tabular}{|c|c|}
\hline \multicolumn{2}{|l|}{ Component } \\
\hline $\mathrm{NaHCO}_{3}$ & $9 \cdot 240$ \\
\hline $\mathrm{Na}_{2} \mathrm{HPO}_{4} \cdot 12 \mathrm{H}_{2} \mathrm{O}$ & $7 \cdot 125$ \\
\hline $\mathrm{NaCl}$ & 0.470 \\
\hline $\mathrm{KCl}$ & $0 \cdot 450$ \\
\hline $\mathrm{Na}_{2} \mathrm{SO}_{4}$ & $0 \cdot 100$ \\
\hline $\mathrm{CaCl}_{2}$ & $0 \cdot 055$ \\
\hline $\mathrm{MgCl}_{2}$ & 0.047 \\
\hline Urea & $0 \cdot 400$ \\
\hline $\mathrm{FeSO}_{4} .7 \mathrm{H}_{2} \mathrm{O}(\mathrm{mg} / \mathrm{l})$ & $36 \cdot 800$ \\
\hline $\mathrm{MnSO}_{4} .7 \mathrm{H}_{2} \mathrm{O}(\mathrm{mg} / \mathrm{l})$ & $19 \cdot 000$ \\
\hline $\mathrm{ZnSO}_{4} .7 \mathrm{H}_{2} \mathrm{O}(\mathrm{mg} / 1)$ & $4 \cdot 400$ \\
\hline $\mathrm{CoCl}_{2} \cdot 6 \mathrm{H}_{2} \mathrm{O}(\mathrm{mg} / \mathrm{l})$ & $1 \cdot 200$ \\
\hline $\mathrm{CuSO}_{4} .5 \mathrm{H}_{2} \mathrm{O}(\mathrm{mg} / 1)$ & 0.980 \\
\hline $\mathrm{Mo}_{7}\left(\mathrm{NH}_{4}\right)_{6} \mathrm{O}_{24} \cdot 4 \mathrm{H}_{2} \mathrm{O}(\mathrm{mg} / \mathrm{l})$ & $0 \cdot 174$ \\
\hline
\end{tabular}

* For details of procedures, see p. 190.

in the equation failed the test to enter. The results are expressed as the final equation variables, i.e. the constant, the multiple correlation coefficient $(R)$, the partial correlation coefficient $(r)$ and the $F$ value of the entered variables. The higher the coefficient $(r)$ assigned to each sugar the more this sugar was needed to produce SCFA. The higher the $F$ value attributed to each sugar the more significantly this sugar was predictive for SCFA production.

\section{RESULTS}

The five fibres were all predominantly composed of arabinose, xylose, glucose and uronic acids (Table 3). Wheat bran and maize were characterized by high contents of arabinose and xylose, a relatively high content of glucose and a low content of uronic acids. On the contrary, sugar beet, pea and cocoa were rich in uronic acids but differed in their main neutral sugar composition; arabinose and glucose were predominant in sugar beet, glucose and xylose in pea, and glucose in cocoa.

The fermentability of the total sugars $v$. time was used to classify the five fibres from the most to the least degraded as follows: sugar beet, cocoa, wheat bran, pea and maize (Fig. 1). Sugar beet was the most rapidly (46.1 (range $43.6-48.7) \%$ at $6 \mathrm{~h}$ ), and completely $(81.9$ 
Table 3. Sugar composition (\% initial dry matter) of fibres*

\begin{tabular}{|c|c|c|c|c|c|c|c|c|}
\hline Source of fibre & Rha & Ara & Xyl & Man & Gal & Glc & $\begin{array}{c}\text { Total } \\
\text { NS }\end{array}$ & Uron \\
\hline Wheat bran & 0.1 & 7.6 & $12 \cdot 5$ & 0.8 & 0.8 & $8 \cdot 5$ & $30-3$ & 1.9 \\
\hline Sugar beet & $1 \cdot 7$ & $17 \cdot 8$ & 1.5 & $1 \cdot 3$ & $4 \cdot 5$ & $22 \cdot 7$ & $49 \cdot 6$ & $19 \cdot 4$ \\
\hline Maize & 0.2 & $10 \cdot 7$ & $16 \cdot 7$ & 0.9 & $3 \cdot 1$ & $12 \cdot 2$ & 43.8 & $3 \cdot 2$ \\
\hline Pea & 0.7 & 3.6 & $11 \cdot 6$ & $0 \cdot 2$ & $1 \cdot 1$ & $50 \cdot 2$ & 67.6 & $14 \cdot 7$ \\
\hline Cocoa & 0.8 & 1.8 & $1 \cdot 8$ & $2 \cdot 6$ & $2 \cdot 9$ & $15 \cdot 8$ & 25.7 & $12 \cdot 9$ \\
\hline
\end{tabular}

Rha, rhamnose; Ara, arabinose; Xyl, xylose; Man, mannose; Gal, galactose; Glc, cellulosic glucose; NS, neutral sugars; Uron, uronic acids.

* Starch of wheat bran and maize is previously enzymically removed. For details of procedures, see p. 190.

(range $81.9-82.0) \%$ at $24 \mathrm{~h}$ ) degraded, whereas maize was least fermented $(11.0$ (range $6 \cdot 2-15 \cdot 8) \%$ at $24 \mathrm{~h}$ ). Cocoa, wheat bran and pea were only partly broken down after $24 \mathrm{~h}$ of incubation, 49.1 (range 47.3-50.9) \%, 43.7 (range 42.5-44.8) \% and 28.7 (range $25 \cdot 2-32 \cdot 2) \%$ respectively. The fermentation of pea began much more slowly than that of cocoa and wheat bran, $8 \cdot 5$ (range $8 \cdot 3-8 \cdot 8$ ) $\%$ compared with 34.4 (range $34 \cdot 2-34 \cdot 7$ ) $\%$ and 35.0 (range $28 \cdot 3-41 \cdot 6$ ) \% respectively after $6 \mathrm{~h}$ incubation.

The respective fermentabilities of the main sugars of the five fibres are represented in Fig. 2. The disappearance of uronic acids always began rapidly and immediately in all fibres. After $6 \mathrm{~h}$ it continued increasing sharply for sugar beet and slightly for cocoa and pea, whereas a plateau was rapidly reached for wheat bran and maize. By contrast, xylose was only slightly degraded except in wheat bran in which this sugar was more fermented than uronic acids. Arabinose in sugar beet, cocoa and pea also largely disappeared, whereas it was almost undegraded in wheat bran and maize. Glucose was only slightly broken down in pea and very poorly fermented in cocoa, maize and wheat bran. Its degradation was high in sugar beet but began more slowly than that of uronic acids and arabinose.

SCFA production was significantly correlated with $\mathrm{pH}$ values $(R 0.93, P=0.0001)$, gas production $(R 0.92, P=0.0001)$ and sugar fermentability $(R 0.91, P=0.0001)$. The production of the main SCFA, i.e. acetic, propionic and butyric acids, was different for the five fibres as shown in Fig. 3. Acetic acid was the major product in the medium with respect to the rate of fibre degradation, whatever the fibre. The incubation of maize, cocoa and pea produced similar concentrations of propionic acid, whereas this acid accumulated in greater amounts during the fermentation of sugar beet and wheat bran. The production of butyric acid was also higher from sugar beet and wheat bran than from cocoa, pea and maize.

With regard to the stepwise multiple linear regression performed to evaluate the involvement of four sugars, i.e. arabinose, xylose, glucose and uronic acids, in SCFA production, the variables of the final regression equation for acetic, propionic and butyric acids are presented in Table 4. For all three equations $R$ was high. Among the four sugars taken into account, only uronic acids, xylose and glucose were inserted in the final equation of the production of acetic acid. Both $r$ and $F$ values of xylose and glucose were similar, but those of uronic acids were higher; the latter, therefore, provided the best predictor. Regarding the production of propionic acid, only glucose, xylose and arabinose were selected in the final equation; glucose showed slightly higher $r$ and $F$ values than arabinose or xylose. In the production of butyric acid, only xylose, glucose and uronic acids entered the final equation but both $r$ and $F$ values associated with xylose were higher than those of glucose and uronic acids. As a whole, the respective $F$ values showed that the amounts of 


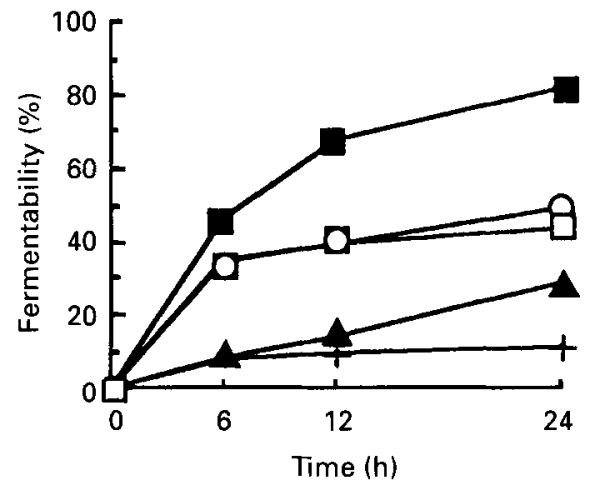

Fig. 1. In vitro fermentability of the total sugars of five fibres: wheat bran $(\square)$, sugar beet $(\square)$, maize $(+)$, pea $(\boldsymbol{A})$ and cocoa $(O)$. Values are the mean of two experiments. Starch of wheat bran and maize has been enzymically removed.
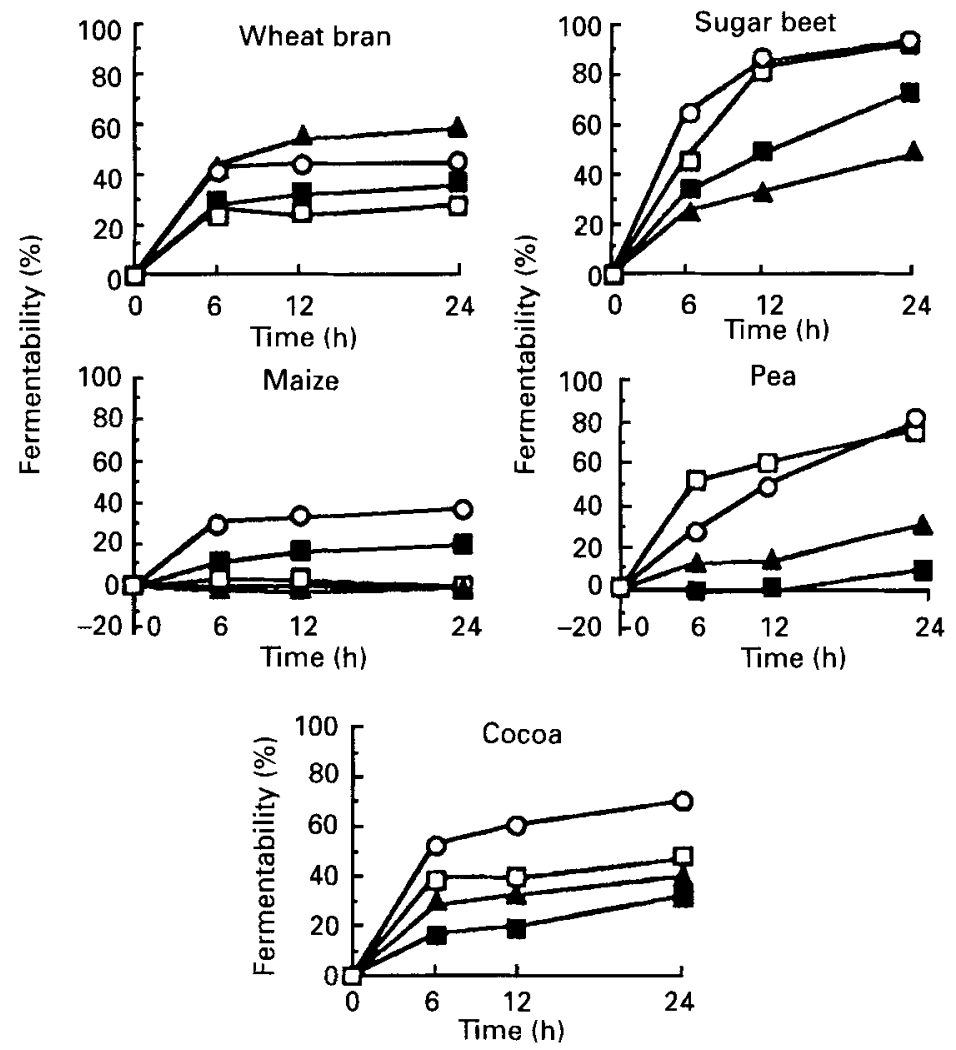

Fig. 2. In vitro fermentability of the main sugars of five fibres: arabinose ( $\square$ ), xylose ( $\mathbf{\Delta})$, glucose ( $\square$ ) and uronic acids $(O)$. Values are the mean of two experiments. Starch of wheat bran and maize has been enzymically removed. 

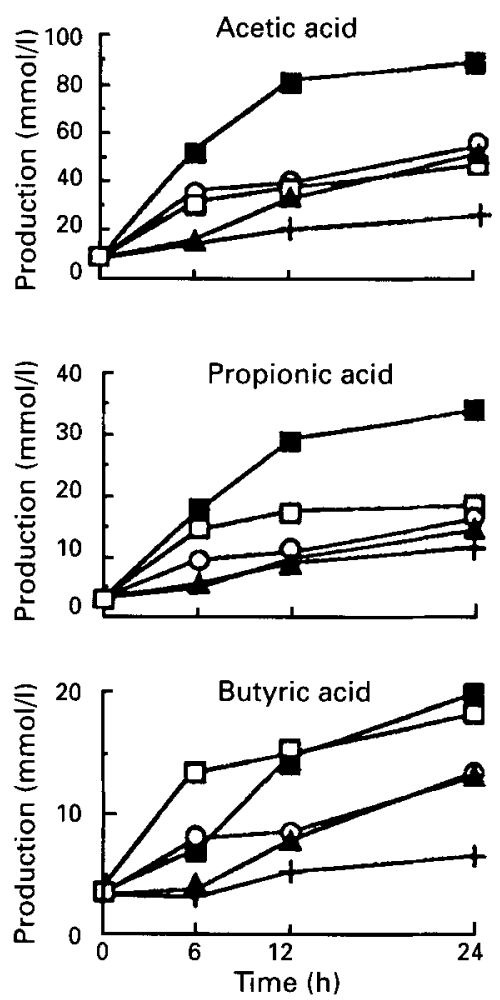

Fig. 3. Production of short-chain fatty acids (acetic, propionic and butyric acids) during the in vitro incubation of five fibres: wheat bran $(\square)$, sugar beet $(\boldsymbol{\square})$, maize $(+)$, pea $(\boldsymbol{\Delta})$ and cocoa $(O)$. Values are the mean of two experiments. Different scales are used for each acid.

Table 4. Variables of the multiple linear regression final equations*

(Values in parentheses are the partial $F$ values assigned to sugars; $n 30(P<0.05)$, e.g. acetic acid $=12.07+0.33$ xylose +0.33 glucose +0.72 uronic acids)

\begin{tabular}{lccc}
\hline \hline & \multicolumn{3}{c}{$r$} \\
\cline { 2 - 4 } & Acetic acid & Propionic acid & Butyric acid \\
\hline Dietary fibre sugars: & & & \\
Arabinose & $\mathrm{NS}$ & $0 \cdot 16(7 \cdot 6)$ & $\mathrm{NS}$ \\
Xylose & $0 \cdot 33(9 \cdot 2)$ & $0 \cdot 11(6 \cdot 8)$ & $0 \cdot 23(42 \cdot 8)$ \\
Glucose & $0.33(12 \cdot 1)$ & $0 \cdot 22(16 \cdot 9)$ & $0 \cdot 08(6 \cdot 6)$ \\
Uronic acids & $0.72(51 \cdot 0)$ & $\mathrm{NS}$ & $0 \cdot 11(11 \cdot 1)$ \\
Constant & $12 \cdot 07$ & 6.51 & $2 \cdot 51$ \\
Multiple $R$ & 0.94 & 0.92 & 0.88 \\
\hline \hline
\end{tabular}

$r$, partial correlation coefficient; NS, not significant.

* For details of procedures, see p. 190.

fermented sugars only accounted for about $32 \%$ in the production of propionic acid whereas they accounted for about 72 and $61 \%$ respectively in the production of acetic and butyric acids. 


\section{DISCUSSION}

The results show that fibre sugars were not equally utilized by human bacteria during in vitro fermentation in terms of rate and extent of degradation together with nature of SCFA produced from these sugars. The chemical nature and the physical arrangement of the sugars in the fibre matrix controlled the rate and extent of degradation, together with the nature of the SCFA produced form these sugars. Uronic acids of sugar beet, cocoa and pea fibres were highly fermented. This is in agreement with numerous results which report that pectins and uronic acids are extensively degraded by colonic bacteria (Van Soest et al. 1983; Stevens \& Selvendran, 1988; Graham et al. 1989; Cherbut et al. 1991). However, the present results conflict somewhat with those of Nyman et al. (1990) which show a low faecal digestibility of uronic acids of carrot, pea and Brussels sprout in rats. Nevertheless, the thermal processing followed by a long frozen storage applied to these vegetables could have altered the cell wall structure thus changing fermentability patterns (Plat et al. 1991; Guillon et al. 1992). In the present study, when compared with the uronic acids of sugar beet and cocoa those of pea were degraded to a lesser extent and much more slowly. Pea fibres are known to contain pectic substances but are also rich in acidic xylans and cellulose (Titgemeyer et al. 1991). Linkages between uronic acids and xylose could explain the low fermentability of both sugars in pea. Indeed, resistance of xylose in polymeric and monomeric forms against fermentation is observed in both in vivo (Graham et al. 1989) and in vitro (Barry et al. 1989) studies respectively. In agreement with these observations, the present results show that xylose was only slightly degraded in all the fibres except wheat bran, as previously reported (Stevens \& Selvendran, 1988). This preferential degradation of the xylose in wheat bran would be due to its arrangement in the cell wall. The hemicelluloses of wheat bran are composed of two fractions (Brillouet \& Mercier, 1981). The major fraction is essentially composed of linear xylans which are preferentially degraded, whereas the minor fraction, mainly composed of highly branched arabinoxylans, are only slightly hydrolysed by bacterial enzymes. These highly-branched arrangements of arabinoxylans would impede the fermentation of arabinose (Salyers et al. 1978; Brillouet \& Mercier, 1981), which could explain the low fermentability of arabinose in wheat bran and maize in our study. By contrast, the degradation of arabinose was probably favoured by its combination with uronic acids of the pectic substances in sugar beet fibres.

Glucose from cellulose in the five fibres was poorly used by bacteria, in agreement with most fermentation or digestibility studies (McBurney \& Thompson, 1989; Nyman et al. 1990; Goodlad \& Mathers, 1991). The crystalline structure of cellulose (Kerley et al. 1988) and its linkage with antibacterial substances such as lignin in wheat bran (Stevens \& Selvendran, 1988) and tannins in cocoa (Brownlee et al. 1990) could explain the low fermentability of glucose. Moreover, the degradation of glucose in the present study always began when acidic sugars had almost totally disappeared. Similar observations are reported in previous studies about the synergistic effects of pectinolytic and cellulolytic enzymes on the degradation of vegetable cell wall (Stevens et al. 1988; Thibault \& Rouau, 1990).

Thus, fermentation of the respective sugars of the fibres depended on their linkages with each other and on the architecture of the cell wall. These structural arrangements were key variables governing the availability of sugars and might consequently be involved in SCFA production. In fact, the fermentation of the five fibres differed significantly in the production of total and individual SCFA, in agreement with the results of McBurney \& Thompson (1989). The production rates of individual SCFA were closely correlated with the fermentabilities of the sugars. We observed the highest concentrations of acetic acid during the fermentation of sugar beet, cocoa and pea, which were the richest in uronic acids, in agreement with in vitro studies showing that uronic acids and pectins induce acetic 
acid formation (McBurney \& Thompson, 1987; Mortensen et al. 1988; Titgemeyer et al. 1991). Indeed, the percentage disappearance of uronic acids was the best predictor of acetic acid concentration. However, the stepwise regression variables calculated (Table 3 ) show that xylose and glucose were less involved in this production. Mortensen et al. (1988) reported that the degradation of pentoses leads to the production of propionic acid. Our results support this finding since fermentabilities of both arabinose and xylose were correlated with the concentration of propionic acid. Glucose was more predictive of the production of propionic acid than pentoses. This result is in accordance with that of Barry et al. (1989) who observed that degradation of monomeric glucose greatly influences the production of propionic acid in vitro. The fermentation of wheat bran and sugar beet, in which xylose and uronic acids respectively were the most fermented sugars, led to a higher production of butyric acid than with the other fibres. Results of the stepwise regression suggest that xylose was the most suitable of the fibre sugars for the production of butyric acid in vitro, whereas glucose and uronic acids were less involved. This is in accordance with the findings of Cheng et al. (1987) who showed that arabinoxylans and $\beta$-glucans in wheat bran are effective in generating butyric acid, and with Mortensen et al. (1988) who observed that butyric acid concentration was higher in assays incubated with uronic acid derivatives. The predictive $F$ values allowed propionic acid to be considered apart from other SCFA since its formation was less predicted by sugar disappearance compared with acetic and butyric acids. This could be related to the different metabolic pathways. Propionic acid formation involves the production of succinate as an intermediate whereas both acetic and butyric acids directly result from pyruvate via acetyl coenzyme A (Miller \& Wolin, 1979). Such a relationship would be interesting to investigate.

The present study suggests first that fibre sugars behaved in vitro in a particular way unconnected with their own fermentability but depending on their associations with the other sugars. The fermentability of fibre sugars is, therefore, mainly based on the chemical structure of fibres. Second, the production of individual SCFA is controlled by the nature and the quantity of the fibre sugars available for the fermentation. It might, thus, be possible to predict which SCFA would be produced during the fermentation of a fibre, as far as the chemical structure of this fibre was already known.

The authors acknowledge SOFALIA (Paris, France) who processed fibres.

\section{REFERENCES}

Auffret, A., Barry, J.-L. \& Thibault, J.-F. (1991). In vitro degradation of chemically treated sugar-beet fibres by human fecal bacteria. Food Hydrocolloids 5, 41-44.

Barry, J.-L., Chourot, J.-M., Bonnet, C., Kozlowski, F. \& David, A. (1989). In vitro fermentation of neutral monosaccharides by ruminal and human fecal microflora. Acta Veterinaria Scandinavica Suppl. 86, 93-95.

Brillouet, J.-M. \& Mercier, C. (1981). Fractionation of wheat bran carbohydrates. Journal of the Science of Food and Agriculture 32, 243-251.

Brownlee, H. E., McEuen, A. R., Hedger, J. \& Scott, I. M. (1990). Anti-fungal effects of cocoa tannin on the witches' broom pathogen Crinipellis perniciosa. Physiological and Molecular Plant Pathology 36, 39-48.

Cheng, B.-Q., Trimble, R. P., Illman, R. J., Stone, B. A. \& Topping, D. L. (1987). Comparative effects of dietary wheat bran and its morphological components (aleurone and pericarp-seed coat) on volatile fatty acid concentrations in the rat. British Journal of Nutrition 57, 69-76.

Cherbut, C., Salvador, V., Barry, J.-L., Doulay, F. \& Delort-Laval, J. (1991). Dietary fibre effects on intestinal transit in man: involvement of their physicochemical and fermentative properties. Food Hydrocolloids 5, 15-22.

Goodlad, J. S. \& Mathers, J. C. (1991). Digestion by pigs of non-starch polysaccharides in wheat and raw peas (Pisum sativum) fed in mixed diets. British Journal of Nutrition 65, 259-270.

Graham, H., Löwgren, W. \& Aman, P. (1989). An in vitro method for studying digestion in the pig. British Journal of Nutrition 61, 689-698.

Guillon, F., Barry, J.-L. \& Thibault, J.-F. (1992). Effect of autoclaving of sugar-beet fibre on its physico-chemical properties and its in vitro degradation by human faecal bacteria. Journal of the Science of Food and Agriculture 60, 69-70. 
Hoebler, C., Barry, J.-L., David, A. \& Delort-Laval, J. (1989). Rapid acid hydrolysis of plant cell wall polysaccharides and simplified quantitative determination of their neutral monosaccharides by gas-liquid chromatography. Journal of Agricultural and Food Chemistry 37, 360-367.

Jouany, J.-P. (1982). Dosage des acides gras volatils (AGV) et des alcools dans les contenus digestifs, les jus d'ensilage, les cultures bactériennes et les contenus de fermenteurs anaérobies (Volatile fatty acid and alcohol determination in digestive contents silage juices, bacterial cultures and anaerobic fermentor contents). Science des Aliments 2, 131-144.

Kerley, M. S., Fahey, G. C., Gould, J. M. \& Iannotti, E. L. (1988). Effects of lignification, cellulose crystallinity and enzyme accessible space on the digestibility of plant cell wall carbohydrates by the ruminant. Food Microstructure 7, 59-65.

McBurney, M. I., Horvath, P. J., Jeraci, J. L. \& Van Soest, P. J. (1985). Effect of in vitro fermentation using human faecal inoculum on the water-holding capacity of dietary fibre. British Journal of Nurition 53, $17-24$.

McBurney, M. I. \& Thompson, L. U. (1987). Effect of human faecal inoculum on in vitro fermentation variables. British Journal of Nutrition 58, 233-243.

McBurney, M. I. \& Thompson, L. U. (1989). In vitro fermentabilities of purified fiber supplements. Journal of Food Science 54, 347-350.

McBurney, M. I. \& Thompson, L. U. (1990). Fermentative characteristics of cereal brans and vegetable fibers. Nutrition and Cancer 13, 271-280.

Miller, T. L. \& Wolin, M. J. (1979). Fermentations by saccharolytic intestinal bacteria. American Joumal of Clinical Nutrition 32, 164-172.

Mortensen, B., Holtug, K. \& Rasmussen, H. S. (1988). Short-chain fatty acid production from mono- and disaccharides in a fecal incubation system: implications for colonic fermentation of dietary fiber in humans. Journal of Nutrition 118, 321-325.

Nishina, P. M. \& Freedland, R. A. (1990). Effects of propionate on lipid biosynthesis in isolated rat hepatocytes. Journal of Nutrition 120, 668-673.

Nyman, M., Schweizer, T. F., Tyren, S., Reimann, S. \& Asp, N.-G. (1990). Fermentation of vegetable fiber in the intestinal tract of rats and effects on fecal bulking and bile acid excretion. Journal of Nutrition 120, 459-466.

Plat, D., Ben-Shalom, N. \& Levi, A. (1991). Changes in pectic substances in carrots during dehydration with and without blanching. Food Chemistry 39, 1-12.

Prosky, L., Asp, N.-G., Schweizer, T. F., De Vries, J. W. \& Furda, I. (1988). Determination of insoluble, soluble, and total dietary fiber in foods and food products: interlaboratory study. Journal of the Association of Official Analytical Chemists 71, 1017-1023.

Sakata, T. (1987). Stimulatory effect of short-chain fatty acids on epithelial cell proliferation in the rat intestine: a possible explanation for trophic effects of fermentable fibre, gut microbes and luminal trophic factors. British Journal of Nutrition 58, 95-103.

Salyers, A. A., Palmer, J. K. \& Wilkins, T. D. (1978). Degradation of polysaccharides by intestinal bacterial enzymes. American Journal of Clinical Nutrition 31, S128-S130.

Stevens, B. J. H. \& Selvendran, R. R. (1988). Changes in composition and structure of wheat bran resulting from the action of human faecal bacteria in vitro. Carbohydrate Research 183, 311-319.

Stevens, B. J. H., Selvendran, R. R., Bayliss, C. E. \& Turner, R. (1988). Degradation of cell wall material of apple and wheat bran by human faecal bacteria in vitro. Journal of the science of Food and Agriculture 44, $151-166$.

Thibault, J.-F. (1979). Automatisation du dosage des substances pectiques par la méthode au métahydroxydiphényl (An automated method for the determination of pectic substances). Lebensmittel-Wissenschaft und Technologie 12, 247-251.

Thibault, J.-F. and Rouau, X. (1990). Studies on enzymic hydrolysis of polysaccharides in sugar-beet pulp. Carbohydrate Polymers 13, 1-16.

Titgemeyer, E. C., Bourquin, L. D., Fahey, G. C. \& Garleb, K. A. (1991). Fermentability of various fiber sources by human fecal bacteria in vitro. American Journal of Clinical Nutrition 53, 1418-1424.

Van Soest, P., Horvath, P., McBurney, M., Jeraci, J. \& Allen, M. (1983). Some in vitro and in vivo properties of dietary fibers from noncereal sources. In Unconventional Sources of Dietary Fiber. Symposium Series no. 214 , pp. 135-141 [I. Furda, editor]. Washington, DC: American Chemical Society. 